\title{
Stereocomplexation of sPMMA-PBD-sPMMA triblock copolymers with isotactic PMMA: 1. Thermal and mechanical properties of stereocomplexes
}

\author{
Jian Ming Yu, Yi-Song Yu, Philippe Dubois and Robert Jérôme
}

University of Liège, Center for Education and Research on Macromolecules, Sart-Tilman, B6, 4000 Liège, Belgium

\begin{abstract}
A novel thermoplastic elastomer consisting of a triblock copolymer (MBM) with outer syndiotactic poly(methyl methacrylate) (sPMMA) blocks associated to an inner polybutadiene (PBD) block has been modified by stereocomplexation with isotactic PMMA (iPMMA). Solution cast films of stereocomplexes have been analysed by thermal analysis as a function of the iPMMA/sPMMA (i/s) mixing ratio and the solvent used for the film casting. Although self-aggregation of iPMMA is currently observed, this phenomenon does not occur in solvent cast films of iPMMA with the MBM copolymers. Extent of complexation depends on the i/s mixing ratio and the casting solvent. At a constant $\mathrm{i} / \mathrm{s}$ ratio, molecular weight of iPMMA has no significant effect on the extent of stereocomplexation. Thermal stability of the stereocomplexes is only affected by the casting solvent, in contrast to tensile strength which is greatly influenced by the mixing ratio of the two PMMA stereoisomers. Tensile strength is increased when increasing amounts of iPMMA are blended with a triblock copolymer of low PMMA content (e.g. 12\%). In case of triblocks of high PMMA content (ca. 30\% or higher), a low i/s ratio $(<1 / 4)$ increases the tensile strength, whereas a high $\mathrm{i} / \mathrm{s}$ mixing ratio (1/2) results in decreasing tensile strength. The same trend is observed for blends of sPMMA - polystyrene (PS)-PBD-PS-sPMMA (MSBSM) pentablock copolymers with iPMMA.
\end{abstract}

Keywords: poly(methyl methacrylate); polybutadiene; stereocomplexation

\section{INTRODUCTION}

Special attention has been paid to thermoplastic elastomers since the discovery of the unique thermomechanical properties of styrene-butadiene-styrene triblock copolymers (SBS). Microphase separation of the polystyrene blocks into glassy microdomains dispersed in the continuous rubbery polybutadiene (PBD) phase results in a physical network of flexible chains. It is the reason why these SBS copolymers exhibit rubber-like properties, independently of any cross-linking reaction. Tensile strength of thermoplastic elastomers depends upon the ability of the hard blocks to maintain a plastic deformation under stress. Thus, the strength decreases sharply as the glass transition temperature $\left(T_{\mathrm{g}}\right)$ of the hard block is approached. The upper service temperature of SBS is accordingly limited to $\mathrm{ca} .70^{\circ} \mathrm{C}$. It would thus be worth substituting polystyrene $\left(T_{\mathrm{g}}=100^{\circ} \mathrm{C}\right)$ for a hard block of a higher service temperature. Among several known examples [1-8], Morton et al. [1] have explored the use of poly $\left(\alpha\right.$-methylstyrene) the $T_{\mathrm{g}}$ of which is higher than polystyrene by $70^{\circ} \mathrm{C}$. The low ceiling temperature of this polymer however makes the synthesis of the triblock copolymer less attractive. Polyethylene sulfide [2] has also been considered as a substitute for polystyrene, but the related triblock copolymers have poor ultimate mechanical properties.

Methyl methacrylate (MMA) is a possible candidate for the hard block. Indeed, syndiotactic PMMA (sPMMA) has a rather high $T_{g}\left(\mathrm{ca} .125^{\circ} \mathrm{C}\right)$ and the additional advantage of forming a stereocomplex with isotactic PMMA (iPMMA). The melting temperature of the stereocomplex is close to $190^{\circ} \mathrm{C}$, which is a very interesting upper service temperature.

Stereocomplexation of iPMMA and sPMMA has been extensively investigated since the first report by Fox et al. [9] on anomalous WAXS patterns for the related blends. These studies have recently been reviewed by Spevacek and Schneider [10].

Formation of iPMMA and SPMMA stereocomplexes has been reported to occur either in the bulk state or in some suitable solvents [11-14]. PMMA stereoisomers would form a 1/2 i-PMMA/s-PMMA complex, that crystallizes as reflected by two melting endotherms. Casting solvent and annealing temperature have a decisive effect on the temperature of melting, or decomposition, of the stereocomplex.

Most of the studies on the stereocomplexation have focused on blends of homo PMMA stereoisomers. Recently, 
Hogen-Esch et al. [3] have reported on the thermal behaviour of blends of iPMMA and PBD-sPMMA diblock copolymers, concluding that the rubbery PBD block does not prevent stereocomplexation from occurring.

Table 1 Molecular characterization of SPMMA-PBD-sPMMA (MBM) triblock and SPMMA-SBS-sPMMA pentablock copolymers

\begin{tabular}{|c|c|c|c|c|c|}
\hline Sample & $\overline{\overline{\pi t}_{n}}\left(\mathrm{x} 10^{-3}\right)^{a}$ & $\overline{\overline{M_{w}} / \overline{M_{\mathrm{n}}}}$ & $\begin{array}{l}\mathrm{PMMA}^{b} \\
(\mathrm{wt} \%)\end{array}$ & $\begin{array}{l}\text { PBD } \\
1,2 \text {-units }(\%)^{b}\end{array}$ & $\begin{array}{l}\text { PMMA } \\
\text { syndio }(\%)^{b}\end{array}$ \\
\hline \multicolumn{6}{|l|}{$\overline{M B M}$} \\
\hline$A$ & $15-61-15$ & 1.10 & 33 & 67 & 77 \\
\hline $\mathrm{B}$ & $6-85-6$ & 1.10 & 12 & 43 & 77 \\
\hline $\mathrm{C}$ & $20-90-20$ & 1.15 & 30 & 42 & 76 \\
\hline $\mathrm{D}$ & $26-7926$ & 1.10 & 40 & 44 & 77 \\
\hline $\mathrm{E}$ & $19-69-19$ & 1.10 & 36 & 42 & 78 \\
\hline $\mathrm{F}$ & $13-41-13$ & 1.10 & 39 & 43 & 76 \\
\hline \multicolumn{6}{|l|}{$M S B S M$} \\
\hline $\mathrm{H}$ & $19-18-79-18-19$ & 1.10 & 25 & 43 & 79 \\
\hline
\end{tabular}

a $\overline{M_{n}}$ was calculated from the copolymer composition and the PBD molecular weight

${ }^{b} \mathrm{H}$ n.m.r. analysis

Table 2 Molecular characteristics of iPMMA homopolymers

\begin{tabular}{|c|c|c|c|c|c|c|c|}
\hline \multirow[t]{2}{*}{ Sample } & \multirow{2}{*}{$\begin{array}{c}\bar{M}_{n}^{4} \\
\left(\times 10^{-3}\right)\end{array}$} & \multirow[t]{2}{*}{$\overline{M_{n+} / \bar{M}_{u}}{ }^{u}$} & \multicolumn{3}{|c|}{ Microstructure $(\%)^{b}$} & \multirow{2}{*}{$\begin{array}{l}T_{\mathrm{g}} \\
-\left(\mathrm{C}^{\circ}\right)^{c}\end{array}$} & \multirow{2}{*}{$\begin{array}{l}T_{\mathrm{g}} \\
\left(\mathrm{C}^{\circ}\right)^{d}\end{array}$} \\
\hline & & & $\overline{\mathrm{i}}$ & $\mathrm{S}$ & $\mathrm{h}$ & & \\
\hline iPMMAl & 3 & 1.15 & 89 & 7 & 4 & 35 & 100 \\
\hline iPMMA2 & 12 & 1.25 & 94 & 3 & 3 & 44 & 130 \\
\hline iPMMA3 & 30 & 1.10 & 90 & 6 & 4 & 50 & 115 \\
\hline sPMMA & 20 & 1.20 & 0 & 77 & 23 & 120 & - \\
\hline
\end{tabular}

a $\overline{u_{n}}$ and $\overline{M_{w}} / \overline{M_{n}}$ as measured by s.e.c. with a polystyrene calibration

${ }^{b}{ }^{1}$ H n.m.r. analysis

${ }^{c}$ D.s.c. analysis at a $20^{\circ} \mathrm{C} \min ^{-1}$ heating rate

d Toluene cast samples

The mechanical properties of blends of iPMMA with sPMMA-polyisobutylene-sPMMA triblock copolymers have also been reported by Kennedy et al. $[5,6]$. Stereocomplexation clearly increases tensile strength of the triblock copolymer. Stereocomplex formation in domains of sPMMA PDMS-sPMMA has recently been demonstrated by Deuring et al. [20] by d.s.c. and d.m.t.a. analysis. No tensile properties have been reported for these stereocomplexes.

This paper deals with the stereocomplexation of iPMMA with sPMMA-PBD-sPMMA triblock copolymers used in different ratios and carried out in various solvents. Stereocomplexation of iPMMA with MSBSM pentablock copolymers will also be considered. It will be essential to prove that the stereocomplex formation occurs rather than the self-aggregation of iPMMA. Then the effect of various experimental parameters on stereocomplexation will be studied. Finally, effect of stereocomplexation on the mechanical properties will be investigated in relation to the $\mathrm{i} / \mathrm{s}$ mixing ratio and the initial PMMA content of block copolymers.

\section{EXPERIMENTAL}

\section{Block copolymerization}

SPMMA-PBD-sPMMA triblock and SPMMA SBS-sPMMA pentablock copolymers were prepared according to the method reported in a previous paper [21]. Briefly, a $2 / 1 \mathrm{tBuLi} / \mathrm{m}-\mathrm{DIB}$ diadduct was used to initiate the anionic polymerization of butadiene in cyclohexane at room temperature. A sample of the living PBD chains was picked out for analysis of molecular weight and polydispersity by size exclusion chromatography (s.e.c). 


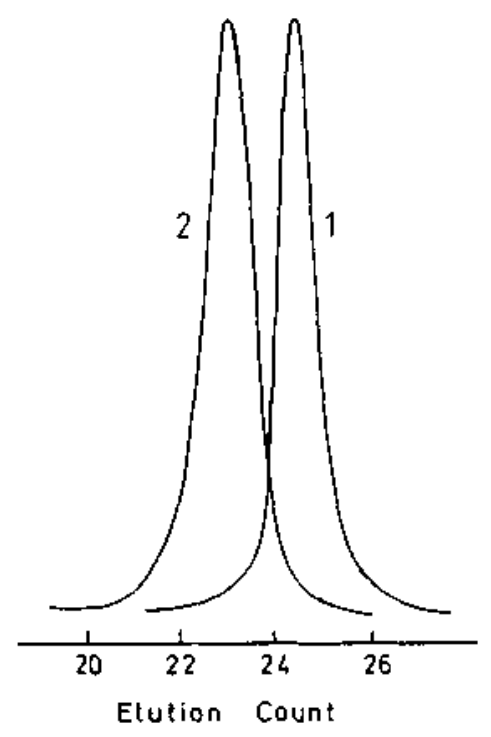

Figure 1 Typical s.e.c. traces for the PBD precursor (trace 1) and MBM triblock copolymer (trace 2) for samples A (Table I)

Then, the PBD chains were end-capped with 1,1-diphenylethylene (DPE) dissolved in THF, before MMA was added and polymerized at $-78^{\circ} \mathrm{C}$. The final copolymer was recovered by precipitation in methanol and dried for 2 days at room temperature under vacuum. Composition was analysed by ${ }^{1} \mathrm{H}$ n.m.r. Molecular weight, polydispersity, composition and microstructure of block copolymers are reported in Table 1.

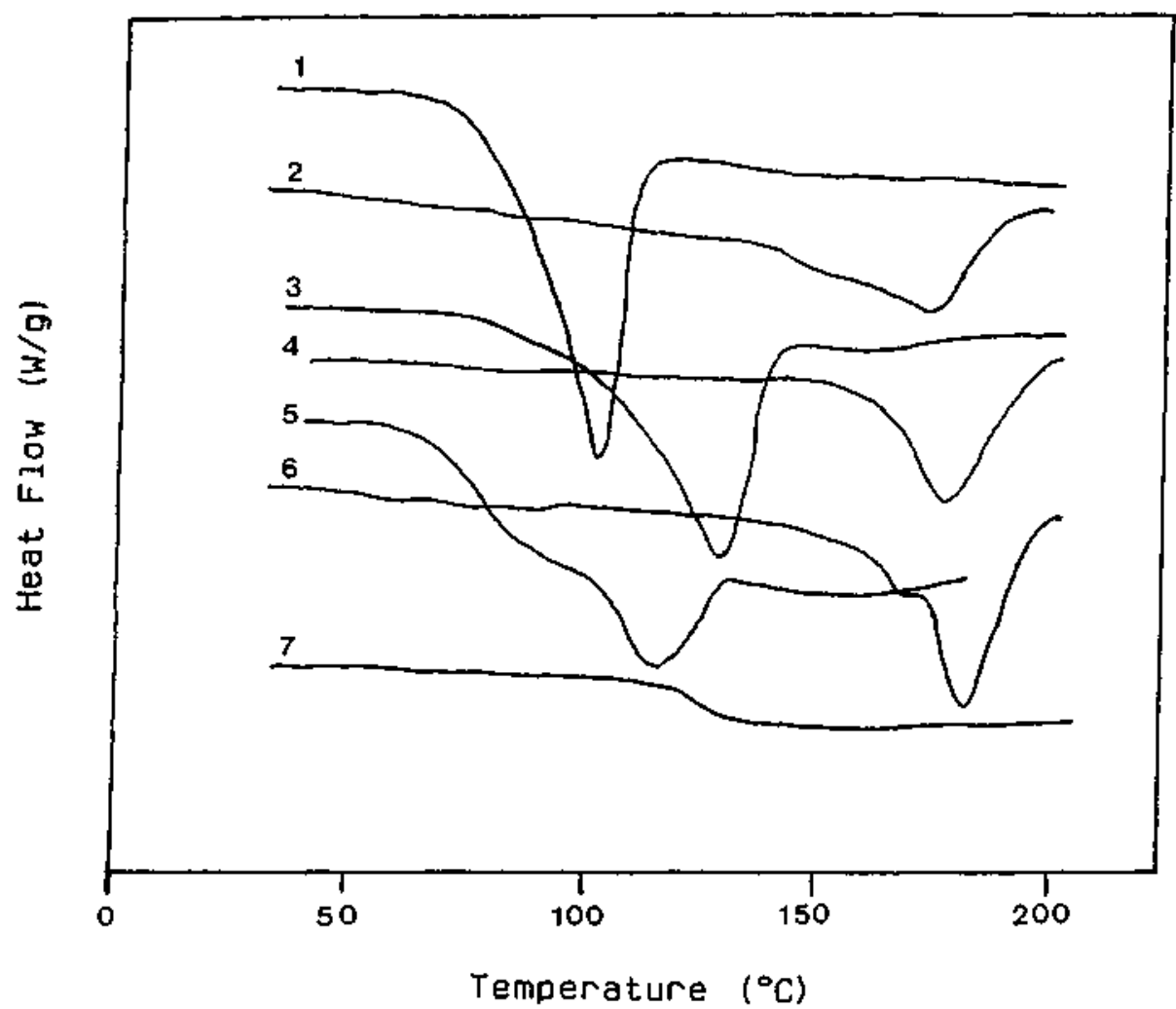

Figure 2 D.s.c. thermograms for the iPMMAs of Table 2 and their blend with triblock copolymer A (Table 1) in a 2/1 s/i mixing ratio: (1) iPMMAl, (2) iPMMAl + A, (3) iPMMA2, (4) iPMMA2 + A, (5) iPMMA3, (6) $i P M M A 3$ $+A$, (7) sPMMA 


\section{Synthesis of PMMA homopolymers}

Isotactic PMMA was prepared in toluene at $-78^{\circ} \mathrm{C}$ with $\mathrm{tBuMgBr}$ as initiator according to a method reported by Hatada et al. [19]. Syndiotactic PMMA was prepared by anionic polymerization in THF at $-78{ }^{\circ} \mathrm{C}$ with the $\mathrm{DPE} / \mathrm{sec}$ - BuLi adduct as an initiator. Molecular weight, polydispersity, tacticity, glass transition and melting temperatures of homoPMMAs are listed in Table 2.

\section{Sample preparation}

Films of block copolymers were prepared by solution casting. A copolymer solution in toluene (6wt $\%$ ) was allowed to evaporate at room temperature for 3 days in a glass Petri dish. The film was then dried for 2 extra days at $40^{\circ} \mathrm{C}$ under vacuum. When stereocomplexes were concerned, a $6 \mathrm{wt} \%$ solution of the copolymer and iPMMA in toluene was prepared at $100^{\circ} \mathrm{C}$. The homogeneous solution was immediately poured into a Petri dish and a clear film with a smooth surface was formed.

\section{Analysis}

Molecular weight and molecular weight distribution were measured by size exclusion chromatography (s.e.c.) at $25^{\circ} \mathrm{C}$ with a Waters GPC 501 apparatus equipped with linear styragel columns. THF was the eluent (flow rate of

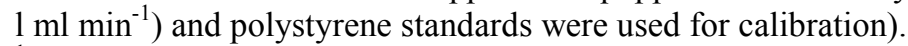

${ }^{1} \mathrm{H}$ n.m.r. spectra were recorded with a Brucker AM-400 spectrometer, by using $\mathrm{CDCl}_{3}$ as a solvent at $25^{\circ} \mathrm{C}$. The 1,2 unit content of the PBD blocks was calculated from the relative intensity of the signals at $4.9 \mathrm{ppm}\left(=\mathrm{CH}_{2}\right.$ of the 1,2 double bond) and $5.4 \mathrm{ppm}(\mathrm{CH}=$ of the 1,2 double bonds and the $-\mathrm{CH}=\mathrm{CH}$ - bonds of the 1,4 units $)$, respectively.

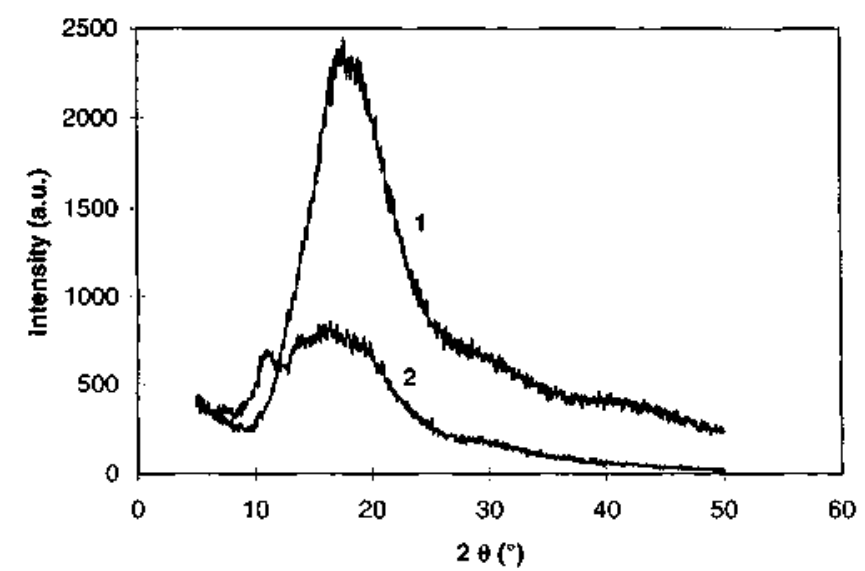

Figure 3 WAXS profile for the block copolymer A (curve 1) and corresponding blends with iPMMA3 in a 2/1 s/i mixing ratio (curve 2)

Composition of the copolymer was calculated from the relative intensity of the signal of the 1,2 units of PBD $(4.9 \mathrm{ppm})$ and the signal of the $0-\mathrm{CH}_{3}$ group of PMMA $(3.6 \mathrm{ppm}) . \bar{M}_{\mathbf{n}}$ of PMMA was calculated from the composition and the PBD molecular weight.

Differential scanning calorimetry (d.s.c.) was carried out at a $20^{\circ} \mathrm{C} \mathrm{min}^{-1}$ heating rate with a DuPont 900 instrument, calibrated with indium. Glass transition temperature was reported as the inflection point of the corresponding heat capacity jump.

Tensile measurements were conducted with a Adamel Lhomargy tensile tester. Microdumbells were cut from solution cast films and extended at $200 \mathrm{~mm} \mathrm{~min}^{-1}$ at room temperature. 

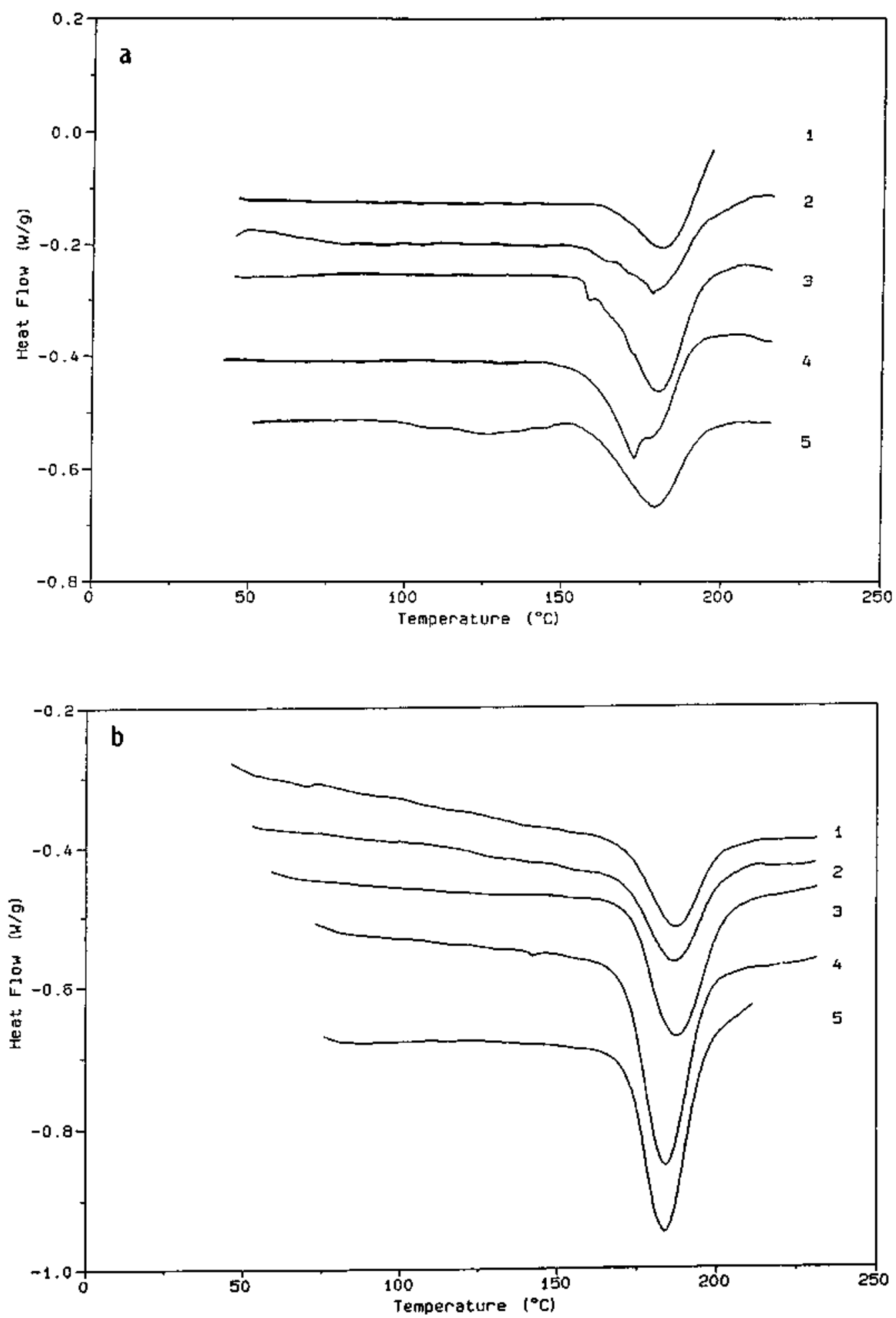

Figure 4 Effect of the s/i mixing ratio on the d.s.c. thermograms of blends of the triblock copolymer $A$ and iPMMA3. Samples cast from a $6 \mathrm{wt} \%$ solution in toluene, s/i mixing ratio: 8/1(1), 4/1(2). 2/1(3), 1.4/1(4), $l / l(s)$. (a) Before annealing, (b) after annealing at 140C under vacuum for $15 \mathrm{~h}$

Strain was measured from the cross-head displacement. Sample thickness and width were about $0.5 \mathrm{~mm}$ and 3.6 $\mathrm{mm}$, respectively. Average values of three independent measurements were reported.

Wide-angle X-ray scattering (WAXS) spectra were recorded using Ni-filtered $\mathrm{Cu} K \alpha$ radiation in $2 \Theta$ transmission mode within the range of $2 \Theta$ from $3^{\circ}$ to $90^{\circ}$. 


\section{RESULTS AND DISCUSSION}

Figure 1 shows the s.e.c. curves of two triblock copolymers used in this study. The symmetric and narrow molecular weight distribution indicates that the copolymers are not contaminated by homopolymer and/or diblock copolymer, in agreement with previous results [21].

\section{Stereocomplexation vs self-aggregation of iPMMA and SPMMA}

Although iPMMA and sPMMA of a high stereoregularity are currently reported to form stereocomplexes, each of them can also self-aggregate. According to the scientific literature [10], the thermal stability of iPMMA and SPMMA stereocomplexes in solution is considerably higher than that of self-aggregated sPMMA of a high stereoregularity, but lower than the stability of self-aggregated iPMMA. It is thus essential to discriminate the formation of iPMMA/sPMMA stereocomplex from the self-aggregation of iPMMA and/or sPMMA.

Films of the three iPMMA samples (Table 2) and blend of each of them with the triblock copolymer A (Table 1) have been cast from toluene and analysed by d.s.c. Thermograms of Figure 2 show the melting endotherm of the iPMMA self-aggregates. The maximum of this endotherm is in the range of 100 to $130^{\circ} \mathrm{C}$. Blends of iPMMA and the block copolymer A show a melting peak at a much higher temperature $\left(\mathrm{ca} .180^{\circ} \mathrm{C}\right)$ compared to the parent iPMMA samples $\left(<130^{\circ} \mathrm{C}\right)$, which is in contrast to the aggregation in solution [10]. These observations reported under the same experimental conditions confirm that stereocomplexation occurs when iPMMA is mixed with the sPMMA block of the sPMMA-PBD-sPMMA triblock copolymer. It may thus be concluded that although iPMMA is prone to self-aggregate, it preferably forms stereocomplexes with sPMMA even when this stereoisomer is part of a block copolymer. This preference indicates that stronger interactions are involved in stereocomplexation compared to iPMMA self-aggregation. Self-aggregation of the sPMMA constitutive component of the triblock copolymer has not been observed in toluene cast films, only a $T_{g}$ at $120^{\circ} \mathrm{C}$ was found in the d.s.c. curve (Figure 2).

Figure 3 shows WAXS patterns of the triblock A and its blend with iPMMA3 (s/i=2/1). The crystalline blend shows a reflection at $2 \Theta=11^{\circ}$, in agreement with previous observation by Challa et al. for sPMMA/ iPMMA stereocomplexes [11] and for stereocomplexation

of sPMMA-b-polydimethylsiloxane-b-sPMMA by iPMMA [20]. No reflection at $2 \Theta=11^{\circ}$ is observed for pure iPMMA [26]. Therefore, WAXS provides a signature for the crystalline stereocomplex of iPMMA and the sPMMA outer blocks of the triblock copolymer.

\section{Dependence of stereocomplexation on experimental parameters}

Stereocomplexation may be influenced by various experimental parameters, such as the sPMMA/iPMMA mixing ratio, the casting solvent, the iPMMA molecular weight and the mechanical stretching of the sample.

Effect of the s/i mixing ratio. The optimum ratio of sPMMA and iPMMA for the stereocomplex formation is a matter of controversy. Although the $2 / 1 \mathrm{~s} / \mathrm{i}$ weight ratio is most often reported [10,14], Miyamoto et al. [15] and Ute et al. [16] have proposed a 1/1 weight ratio and Spevacek et al. [17] and Katime et al. [18] have published a $1.5 / 1$ weight ratio. One of the reasons for this discrepancy might be a difference in the PMMA stereoregularity. In order to know whether the blending ratio of iPMMA and the sPMMA block of triblocks has an effect on stereocomplexation, triblock A has been blended with iPMMA3 in various ratios. The d.s.c. thermograms (Figure 4a) show an endotherm that corresponds to the melting of the stereocomplex at $180^{\circ} \mathrm{C}$, whatever the s/i ratio in the range of $1 / 1$ to $8 / 1$ (Table 3). The melting enthalpy $\left(\Delta H_{\mathrm{m}}\right)$, which is also reported in Table 3, goes through a maximum at the $2 / 1 \mathrm{~s} / \mathrm{i}$ molar ratio.

Thermal data are also reported in Table 3 and Figure $4 b$ for the samples annealed at $140^{\circ} \mathrm{C}$ for $15 \mathrm{~h}$. This annealing at a temperature higher than $T_{\mathrm{g}}$ of $\mathrm{sPMMA}\left(130^{\circ} \mathrm{C}\right)$ has been carried out in order to eliminate the solvent. 
Table 3 Effect of the mixing ratio of iPMMA3 and the triblock copolymer $A$ on the stereocomplexation

\begin{tabular}{|c|c|c|c|c|c|}
\hline Sample $^{a}$ & $\begin{array}{l}\text { Composition } \\
(\mathrm{s} / \mathrm{i})\end{array}$ & $\begin{array}{l}\boldsymbol{T}_{\mathrm{m}} \\
\text { Ann }\end{array}$ & & $\begin{array}{l}\boldsymbol{H}_{\boldsymbol{m}} \\
\text { Anne }\end{array}$ & $\mathrm{As} \mathrm{cast}^{b}$ \\
\hline$\overline{\mathrm{AC} 1}$ & $8 / 1$ & 181 & 186 & 16.0 & 17.6 \\
\hline $\mathrm{AC} 2$ & $4 / 1$ & 179 & 187 & 19.8 & 20.0 \\
\hline $\mathrm{AC} 3$ & $2 / 1$ & 180 & 187 & 27.5 & 27.4 \\
\hline $\mathrm{AC} 4$ & $1.4 / 1$ & 180 & 184 & 23.5 & 25.8 \\
\hline AC5 & $1 / 1$ & 179 & 184 & 16.6 & 23.4 \\
\hline
\end{tabular}

a Prepared by solvent casting of a $6 \mathrm{wt} \%$ solution in toluene

${ }^{b}$ Dried at $40^{\circ} \mathrm{C}$ under vacuum up to constant weight ${ }^{c}$ At $140^{\circ} \mathrm{C}$ under vacuum for $15 \mathrm{~h}$

Table 4 Effect of the casting solvent on stereocomplexation of iPMMA3 and the MBM block copolymer A

\begin{tabular}{|c|c|c|c|c|c|}
\hline Sample $^{a}$ & Casting solvent & $\begin{array}{l}\boldsymbol{T}_{\boldsymbol{m}} \\
\text { Ann }\end{array}$ & & $\begin{array}{l}\Delta H_{m} \\
\text { Anne }\end{array}$ & As cast $^{c}$ \\
\hline$\overline{\mathrm{AC} 6}$ & Chloroform & 160 & 182 & 16.8 & 11.0 \\
\hline $\mathrm{AC} 7$ & Cyclohexane/THF ${ }^{b}$ & 169 & 181 & 22.9 & 17.3 \\
\hline $\mathrm{AC} 3$ & Toluene & 180 & 187 & 17.5 & 27.4 \\
\hline AC8 & THF & 185 & 189 & 31.0 & 34.3 \\
\hline AC9 & $\mathrm{MEK} / \mathrm{THF}^{b}$ & 186 & 191 & 21.0 & 29.6 \\
\hline
\end{tabular}

${ }^{a}$ Prepared by casting a $6 w t \%$ solution; $s / i=2 / 1$

${ }^{b}$ Composition $1 / 9(v / v)$

${ }^{c}$ Dried at $40^{\circ} \mathrm{C}$ under vacuum up to constant weight

${ }^{d}$ At $140^{\circ} \mathrm{C}$ under vacuum for $15 \mathrm{~h}$

Figure 5 and Table 3 show that the maximum in the melting enthalpy $\left(\Delta H_{\mathrm{m}}\right)$ is again observed at the $2 / 1 \mathrm{~s} / \mathrm{i}$ ratio. However, in contrast to the $1 / 1 \mathrm{~s} / \mathrm{i}$ mixing ratio, $\Delta H_{m}$ for the $2 / 1 \mathrm{~s} / \mathrm{i}$ ratio remains unchanged upon annealing, indicating that the equilibrium was already reached for this sample.

Starting from a $1 / 1$ ratio, the crystallinity increases when the $1 / 1 \mathrm{~s} / \mathrm{i}$ blend is added with an increasing excess of sPMMA block known for non-aggregation. Beyond the 2/1 molar ratio, the degree of crystallinity decreases, indicating that more than a two-fold excess of sPMMA block perturbs the stereocomplexation with iPMMA. This observation supports the general statement that the optimum s/i molar ratio is $2 / 1$ for PMMA stereocomplexation. This process is not basically perturbed when one of the stereoisomers is part of a block copolymer.

Effect of the casting solvent. The solvent used in the film preparation might have an important effect on the stereocomplex formation when a block copolymer is involved. As a rule, stereocomplexation of homo PMMAs does not strongly depend on the solvent polarity. It indeed occurs in polar solvents, such as DMF and THF, and in apolar solvents, such as toluene and benzene [10]. However, the availability of the sPMMA block of MBM triblock copolymers for stereocomplexation with iPMMA is controlled by the immiscibility of PBD and sPMMA. In solution, a microphase separation can occur depending on the selectivity of the solvent toward the constitutive blocks. Blends of iPMMA3 and triblock copolymer A have been prepared in different solvents (Table 4). Chloroform, toluene and THF are common solvents for PBD and sPMMA blocks. Cyclohexane is a selective solvent for PBD, and methyl ethyl ketone (MEK) selectively dissolves PMMA. Since the MBM copolymer is insoluble in cyclohexane and MEK, a mixture of each of them with THF has also been considered in the sample preparation. As reported in the scientific literature on PMMA stereocomplexation, chloroform is considered as a non-complexing solvent, whereas THF and toluene are strong complexing solvents [10] . The effect of solvent on the stereocomplex formation can be inferred from d.s.c. data shown in Figure $6 a$. Furthermore, the melting temperature $\left(T_{\mathrm{m}}\right)$ and the melting enthalpy $\left(\Delta H_{m}\right)$ of stereocomplex formed in a series of solvents are listed in Table 4. 


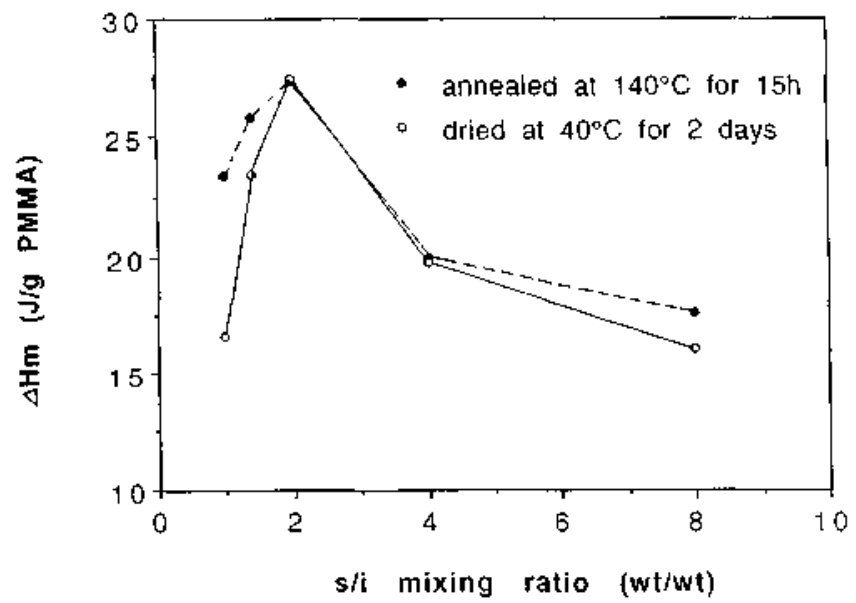

Figure 5 Dependence of the melting enthalpy $\left(\Delta H_{m}\right)$ of the same samples as in Figure 4 on the s/i mixing ratio; ( -) cast films. (---) films annealed at $140^{\circ} \mathrm{C}$ under vacuum for $15 \mathrm{~h}$

The thermal stability $\left(T_{\mathrm{m}}\right)$ is the highest for stereocomplexes formed in toluene, THF and a MEK/THF mixture, i.e. in solvents which are known to promote stereocomplexation of homo PMMAs stereoisomers (toluene, THF) and are either common solvents for the constitutive blocks of the copolymers (toluene, THF) or better solvent for PMMA compared to PBD (MEK/THF mixture). The observation is basically independent of the annealing of the samples. Although added with THF, cyclohexane which is a non-solvent for PMMA and chloroform which is a non-complexing solvent have an unfavourable effect on the melting temperature. This effect is particularly large before the annealing of the samples at $140^{\circ} \mathrm{C}$. It is worth noting that in chloroform, a non-complexing solvent but a common solvent for PBD and PMMA, stereocomplexation occurs to some extent. The melting enthalpy is however small compared to values for the annealed samples formed in all the other solvents. Moreover, the original melting range is broad, from 120 to $180^{\circ} \mathrm{C}$ with a maximum at $160^{\circ} \mathrm{C}$ (Figure $6 a$ ). This indicates the formation of rather small crystallites of a broad distribution in size and perfection.

As a rule, the annealing at $140^{\circ} \mathrm{C}$, i.e. a temperature higher than $T_{g}$ of sPMMA $\left(130^{\circ} \mathrm{C}\right)$, makes the effect of solvent on the thermal stability of the stereocomplexes less pronounced (Table 4 and Figure 6b). When the melting enthalpy is concerned, the annealing significantly increases $\Delta H_{\mathrm{m}}$ for samples AC3, AC8 and AC9 (Table 4), which have the highest melting temperature. In contrast, $\Delta H_{\mathrm{m}}$ of the less thermally stable stereocomplexes (samples AC6 and AC7; Table 4) is decreased upon annealing. This observation is consistent with the partial melting of samples AC6 and AC7 at $140^{\circ} \mathrm{C}$ (Figure 6a), which is responsible for the persistence of less (smaller $\Delta H_{\mathrm{m}}$ ) although more stable (high $T_{\mathrm{m}}$ ) crystallites. The annealing of the originally better crystallized samples (AC3, AC8 and AC9) improves both the degree of crystallinity and thermal stability of the stereocomplex.

Effect of the iPMMA molecular weight and sample stretching. Kennedy et al. [6] have reported that when the molecular weights of iPMMA and sPMMA are very different from each other, stereocomplexation does not occur significantly even upon annealing. In this study, copolymer E with a sPMMA block of a 19000 molecular weight has been blended with 3 iPMMA samples, the molecular weight of which is in the range from 3000 to 30 000 (Table 2). Table 5 shows that the thermal stability $\left(T_{\mathrm{m}}\right)$ and the melting enthalpy $\left(\Delta H_{\mathrm{m}}\right)$ of the stereocomplex are essentially independent of the iPMMA molecular weight at least in the range under consideration.

When blends of a MBM triblock copolymer and iPMMA are uniaxially deformed until rupture, the melting temperature of the stereocomplex does not change too much, whereas the melting enthalpy $\left(\Delta H_{\mathrm{m}}\right)$ is decreased as a result of the partial destruction of crystallites.

Effect of stereocomplexation on the copolymer properties When a MBM triblock copolymer is blended with iPMMA, the phase morphology has to change so as to accommodate iPMMA in the sPMMA microdomains. The mechanical properties could change accordingly. 

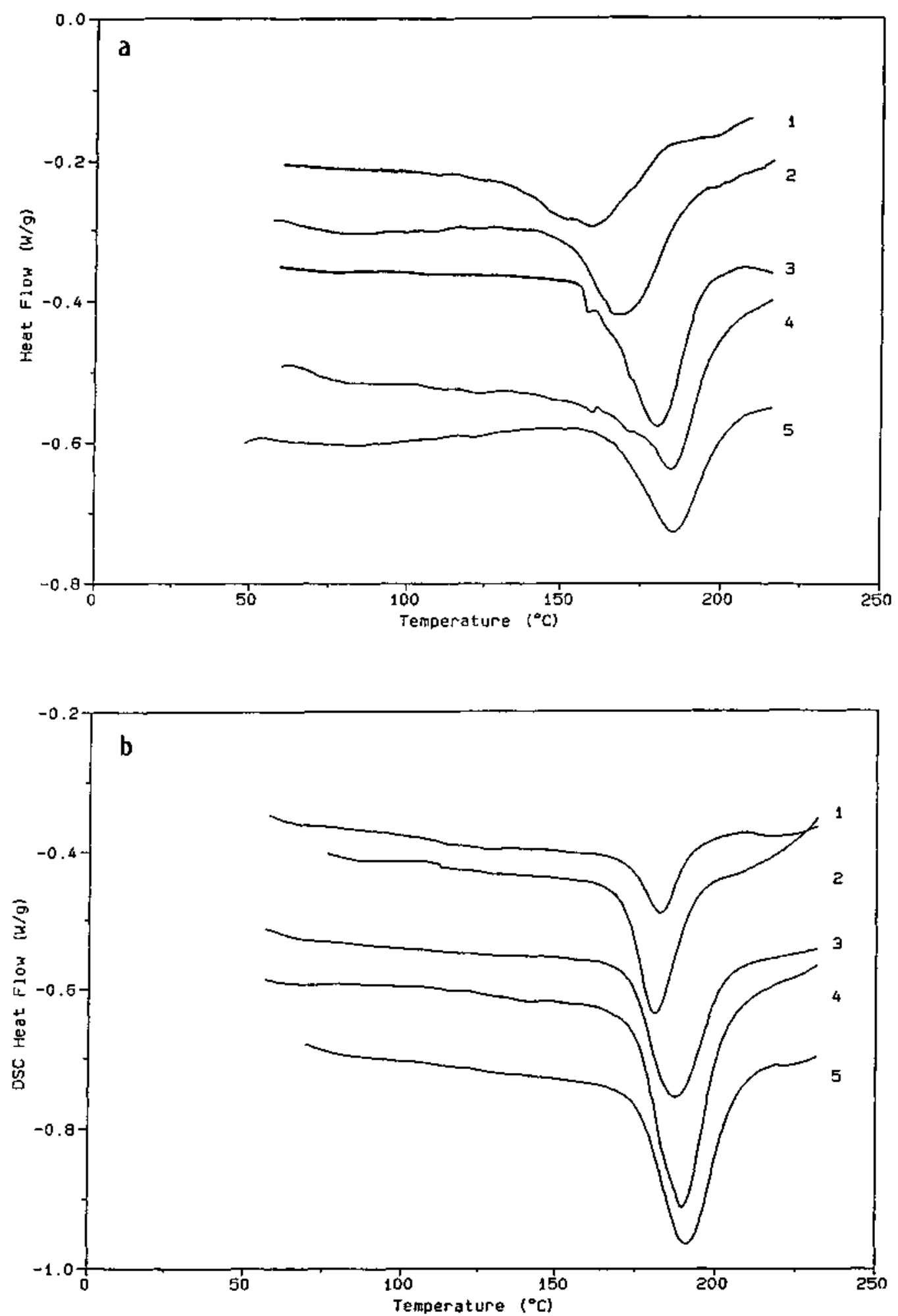

Figure 6 Effect of the casting solvent on the d.s.c. thermograms of blends of copolymer $A$ and iPMMA3 (s/i= 2/1) cast from a $6 w t \%$ solution in chloroform (1), cyclohexane/THF (1/9) (2), toluene (3), THF (4) and MEK/THF (1/9) (5). (a) As cast films, (b) films annealed at $140^{\circ} \mathrm{C}$ under vacuum for $15 \mathrm{~h}$

Five triblock copolymers B to F (Table 1) have been blended with iPMMA3 in various s/i ratios from 8/1 to 2/1. Table 6 shows that glass transition temperature, melting temperature and melting enthalpy depend on the blend composition. These samples have the same thermal stability $\left(T_{\mathrm{m}}: \mathrm{ca} .180^{\circ} \mathrm{C}\right)$ as the compounds discussed before and the melting enthalpy $\left(\Delta H_{\mathrm{m}}\right)$ reaches a maximum for the $2 / 1 \mathrm{~s} / \mathrm{i}$ mixing ratio. Figure 7 shows the d.s.c. trace typical of blends of the triblock copolymer B and iPMMA3 of different mixing ratios. Stereocomplexation 
also occurs when a MSBSM pentablock is used instead of a MBM triblock copolymer. Comparable melting temperature and enthalpy are observed.

Effect on $T_{g}$. According to Table 6, stereocomplexation does not alter $T_{g}$ of the rubbery phase, whatever the block copolymer used, i.e. various MBM triblocks or a MSBSM pentablock.

Table 5 Effect of the iPMMA molecular weight and the sample stretching on stereocomplexation of iPMMA and the $M B M$ copolymer $E$ at a $2 / 1$ s/i mixing ratio

\begin{tabular}{|c|c|c|c|c|c|c|}
\hline \multirow[t]{2}{*}{ Sample $^{a}$} & \multirow[t]{2}{*}{ iPMMA $^{b}$} & \multirow[t]{2}{*}{$\mathrm{T}_{\mathrm{g}}\left({ }^{\circ} \mathrm{C}\right) \mathrm{PBD}$} & \multicolumn{2}{|c|}{ Before stretching $^{c}$} & \multicolumn{2}{|c|}{ After stretching } \\
\hline & & & $\begin{array}{l}\mathrm{T}_{\mathrm{m}} \\
\left({ }^{\circ} \mathrm{C}\right) \\
\end{array}$ & $\begin{array}{l}\Delta H_{\mathrm{m}} \\
\left(\mathrm{Jg}^{-1} \mathrm{PMMA}\right)\end{array}$ & $T_{\mathrm{m}}\left({ }^{\circ} \mathrm{C}\right)$ & $\begin{array}{l}\Delta H_{\mathrm{m}} \\
\left(\mathrm{Jg}^{-1} \mathrm{PMMA}\right)\end{array}$ \\
\hline$\overline{\mathrm{E}}$ & - & -62 & - & - & - & \\
\hline El & iPMMAl & -61 & 171 & 26.5 & 179 & 20.0 \\
\hline $\mathrm{E} 2$ & iPMMA2 & -62 & 173 & 27.0 & 180 & 21.3 \\
\hline E3 & iPMMA3 & -60 & 180 & 28.0 & 178 & 21.0 \\
\hline
\end{tabular}

${ }^{\text {a }}$ Prepared by casting a $6 \mathrm{wt} \%$ solution in toluene

b See Table 2

${ }^{c}$ D.s.c. was carried out after the sample was stretched at a constant rate of $200 \mathrm{~mm} \mathrm{~min}^{-1}$ until rupture

Table 6 Thermal properties of MBM triblock and MSBSM pentablock copolymers and their stereocomplex with iPMMA3

\begin{tabular}{|c|c|c|c|c|c|c|c|}
\hline Sample $^{a}$ & Copolymer & iPMMA & $(\mathrm{s} / \mathrm{i})$ & $\begin{array}{l}T_{g l}^{b} \\
\left({ }^{\circ} \mathrm{C}\right)\end{array}$ & $\begin{array}{l}T_{g 2} \\
\left({ }^{\circ} \mathrm{C}\right)\end{array}$ & $\begin{array}{l}T_{m} \\
\left({ }^{\circ} \mathrm{C}\right)\end{array}$ & $\Delta H_{\mathrm{m}}^{c}\left(\mathrm{Jg}^{-1}\right)$ \\
\hline \multicolumn{8}{|l|}{$\overline{M B M}$} \\
\hline B & B & - & $1 / 0$ & -63 & - & - & - \\
\hline $\mathrm{BC} 1$ & B & iPMMA3 & $8 / 1$ & -62 & - & - & - \\
\hline $\mathrm{BC} 2$ & B & iPMMA3 & $4 / 1$ & -63 & - & 180 & 16.7 \\
\hline $\mathrm{BC} 3$ & B & iPMMA3 & $2 / 1$ & -62 & - & 178 & 27.1 \\
\hline $\mathrm{C}$ & $\mathrm{C}$ & - & $1 / 0$ & -67 & 132 & - & - \\
\hline $\mathrm{CC} 1$ & $\mathrm{C}$ & iPMMA3 & $8 / 1$ & -67 & 120 & 183 & 12.7 \\
\hline $\mathrm{CC} 2$ & $\mathrm{C}$ & iPMMA3 & $4 / 1$ & -66 & 108 & 183 & 23.0 \\
\hline $\mathrm{CC} 3$ & $\mathrm{C}$ & iPMMA3 & $2 / 1$ & -65 & 92 & 182 & 26.0 \\
\hline D & D & - & $1 / 0$ & -62 & 130 & - & - \\
\hline $\mathrm{DC} 1$ & D & iPMMA3 & $8 / 1$ & -62 & 121 & 186 & 10.9 \\
\hline $\mathrm{DC} 2$ & D & iPMMA3 & $4 / 1$ & -62 & 112 & 188 & 19.1 \\
\hline DC3 & $\mathrm{D}$ & iPMMA3 & $2 / 1$ & -62 & 95 & 187 & 32.0 \\
\hline $\mathrm{F}$ & $\mathrm{F}$ & - & $1 / 0$ & -62 & 115 & - & - \\
\hline $\mathrm{FC}$ & $\mathrm{F}$ & iPMMA3 & $2 / 1$ & -61 & 85 & 180 & 26.0 \\
\hline \multicolumn{8}{|l|}{$M S B S M$} \\
\hline $\mathrm{H}$ & $\mathrm{H}$ & - & $1 / 0$ & -62 & - & - & - \\
\hline $\mathrm{HC}$ & $\mathrm{H}$ & iPMMA3 & $2 / 1$ & -63 & - & 185 & 28.8 \\
\hline
\end{tabular}

${ }^{\text {a }}$ Prepared by casting a $6 \mathrm{wt} \%$ solution in toluene; drying at $40{ }^{\circ} \mathrm{C}$ under vacuum up to constant weight

b $\mathrm{T}_{\mathrm{g} 2}$ is an additional $\mathrm{T}_{\mathrm{g}}$ observed in the second scan

c $\Delta \mathrm{H}_{\mathrm{m}}$ is the melting enthalpy per gram of total PMMA

This observation indicates that the PBD phase is completely immiscible with iPMMA, since mobility of the PBD chains is not perturbed by changes in size and geometry of the dispersed PMMA microdomains. The hard phase shows no $T_{\mathrm{g}}$ for the first d.s.c. scan, only the melting of the sPMMA/iPMMA stereocomplex is observed. Since the stereocomplex recrystallization from the melt is a very slow process, a $T_{g}$ is observed, although not for all the samples when the d.s.c. analysis is repeated. Actually the sample is first heated at $20^{\circ} \mathrm{C} \mathrm{min}^{-1}$ until $200^{\circ} \mathrm{C}$. It is then cooled down to $0^{\circ} \mathrm{C}$ at $5^{\circ} \mathrm{C} \mathrm{min}^{-1}$ and heated again at the rate of $20^{\circ} \mathrm{C} \mathrm{min}^{-1}$. As a rule, the $T_{g}$ for the hard phase decreases as the iPMMA content is increased until reaching the $2 / 1 \mathrm{~s} / \mathrm{i}$ mixing ratio. This observation is qualitatively consistent with the lower $T_{\mathrm{g}}$ of iPMMA3 $\left(50^{\circ} \mathrm{C}\right)$ compared to $\operatorname{sPMMA}\left(\mathrm{ca} .125^{\circ} \mathrm{C}\right)$. 
Effect on the stress-strain behaviour. Addition of iPMMA to MBM block copolymers might change the stressstrain behaviour since the phase morphology

could be altered. Kennedy et al. [6] have shown that stereocomplexation of iPMMA and the sPMMA blocks of sPMMA-polyisobutylene-sPMMA triblocks enhanced the tensile strength of the copolymers. The question is now addressed to know whether this conclusion holds for the MBM triblock and MSBSM pentablock copolymers considered in this study.

Table 7 lists stress at the yield point, ultimate tensile strength, elongation at break and permanent set at $100 \%$ elongation for $30 \mathrm{~min}$ for a series of blends of iPMMA3 with triblock copolymers B to $\mathrm{F}$ and pentablock $\mathrm{H}$ (Table 6). It must be noted that all the investigated block copolymers are ductile.

Blends of copolymer B of a low sPMMA content (12 wt\%) (Table 1) with iPMMA3 have been first studied at three s/i mixing ratios (Table 7, Figure 8). There is no dramatic modification in the stress-strain behaviour of the original triblock copolymer upon stereocomplexation. There is a slight increase in the ultimate properties (Figure 8 a) and a significant increase in the initial modulus which corresponds to the slope of the stress-strain curve at very small strains (Figure $8 b$ ) when iPMMA is added until a $2 / 1 \mathrm{~s} / \mathrm{i}$ mixing ratio.

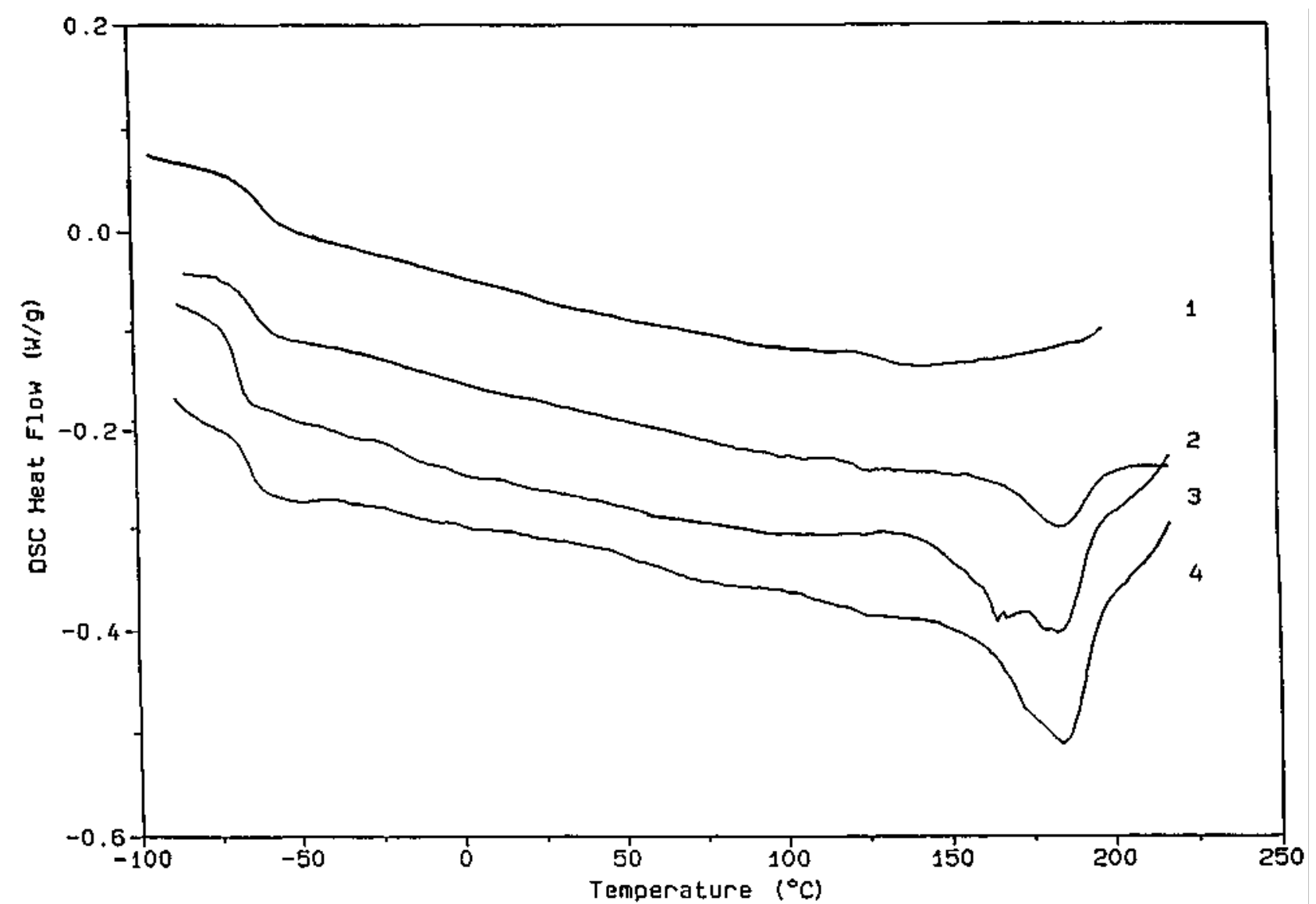

Figure 7 D.s.c. traces for copolymer B and blends with iPMMA3 cast from a 6 wt\% solution in toluene, s/i mixing ratio: $1 / 0$ (1), 8/1 (2), 4/1 (3), 2/1 (4)

The MBM triblock copolymer C of a higher PMMA content (30wt $\%)$ is involved in the next series of blends. Figure 9 shows that a yield point is observed as soon as iPMMA is added and a stereocomplex is formed ( $/ \mathrm{i}=$ $8 / 1)$. When the relative amount of iPMMA is further increased $(\mathrm{s} / \mathrm{i}=4 / 1$ and $2 / 1)$, there is a remarkable increase in modulus. 
Published in: Polymer (1997), vol. 38, iss. 9, pp. 2143-2154

Status: Postprint (Author's version)

Table 7 Mechanical properties of MBM triblock and MSBSM pentablock copolymers and of their stereocomplex with iPMMA

\begin{tabular}{|c|c|c|c|c|c|c|}
\hline Sample $^{a}$ & $\mathrm{~s} / \mathrm{i}$ & $\begin{array}{l}\text { PMMA } \\
(\mathrm{wt} \%)^{b}\end{array}$ & $\begin{array}{l}\text { Stress at yield } \\
\text { point }(\mathrm{MPa})\end{array}$ & $\begin{array}{l}\text { Ultimate tensile } \\
\text { strength } \\
(\mathrm{MPa})\end{array}$ & $\begin{array}{l}\text { Elongation at } \\
\text { break }(\%)\end{array}$ & $\begin{array}{l}\text { Permanent } \\
\text { set } \\
(\%)^{c}\end{array}$ \\
\hline B & $1 / 0$ & 12 & - & 15 & 1350 & 6 \\
\hline $\mathrm{BC} 1$ & $8 / 1$ & 13 & - & 17 & 1400 & 7 \\
\hline $\mathrm{BC} 2$ & $4 / 1$ & 15 & - & 19 & 1500 & 7 \\
\hline $\mathrm{BC} 3$ & $2 / 1$ & 17 & - & 19 & 1600 & 8 \\
\hline $\mathrm{C}$ & $1 / 0$ & 30 & - & 23 & 880 & 7 \\
\hline $\mathrm{CCO}$ & $4 / 1^{d}$ & 35 & - & 10 & 320 & 10 \\
\hline $\mathrm{CC} 1$ & $8 / 1$ & 33 & 4 & 28 & 890 & 10 \\
\hline $\mathrm{CC} 2$ & $4 / 1$ & 35 & 9 & 27 & 820 & 14 \\
\hline $\mathrm{CC} 3$ & $2 / 1$ & 39 & 10 & 18 & 760 & 17 \\
\hline $\mathrm{D}$ & $1 / 0$ & 40 & 5 & 31 & 780 & 9 \\
\hline $\mathrm{DC} 1$ & $8 / 1$ & 43 & 12 & 33 & 820 & 15 \\
\hline DC2 & $4 / 1$ & 45 & 14 & 28 & 800 & 20 \\
\hline DC3 & $2 / 1$ & 50 & 16 & 21 & 740 & 27 \\
\hline $\mathrm{F}$ & $1 / 0$ & 39 & - & 33 & 900 & 7 \\
\hline $\mathrm{FC}$ & $2 / 1$ & 50 & 7 & 21 & 850 & 23 \\
\hline $\mathrm{H}$ & $1 / 0$ & 25 & - & 25 & 800 & 33 \\
\hline $\mathrm{HC}$ & $2 / 1$ & 33 & 20 & 17 & 700 & 60 \\
\hline
\end{tabular}

${ }^{a}$ Same preparation as in Table 6

b Total PMMA content $(\mathrm{s}+\mathrm{i})$

' Ratio of the unrecoverable deformation for the sample elongated at $100 \%$ for 30 min to the initial length

${ }^{\text {d }}$ Mixture of triblock copolymer C with sPMMA homopolymer 

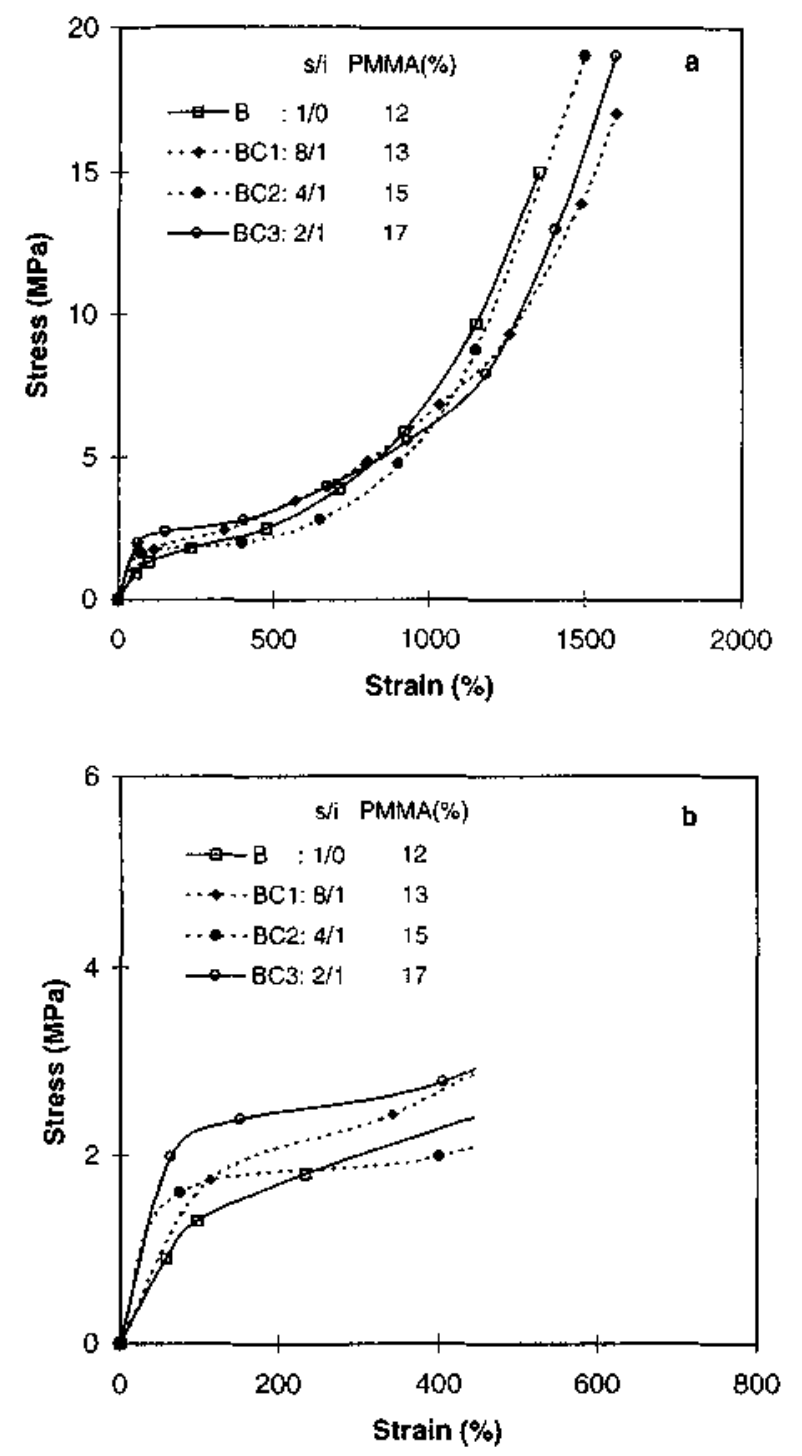

Figure 8 Stress-strain curves for the MBM triblock copolymer B and blends with iPMMA3 at different s/i mixing ratios, (a) Full curves. (b) curves in the small strain region

The ultimate properties are adversely affected by the addition of iPMMA, but only at the extreme mixing ratio of 2/1 (Table 7, Figure 9a). The yielding and the increase in modulus which are observed at the 4/1 s/i ratio (Figure $9 b)$ undoubtedly result from the formation of the semi-crystalline stereocomplex. Indeed substitution of homo sPMMA for homo iPMMA, all the other conditions being the same, does not promote any yielding nor increase in modulus. The main effect is a substantial decrease in the ultimate properties of the original triblock. Yielding is known to occur in SBS thermoplastic elastomers when the content of the polystyrene blocks is high enough to provide the hard microdomains with connectivity [23-25]. It is thus not surprising that yielding occurs when iPMMA is added to the MBM triblock $\mathrm{C}$ of a high $\mathrm{SPMMA}$ content $(30 \mathrm{wt} \%$ ) rather than to the triblock $\mathrm{B}$ that only contains $12 \mathrm{wt} \%$ sPMMA. It is clear that formation of a semi-crystalline sPMMA/iPMMA stereocomplex is favourable to the interconnection of the hard phase, since when the hard phase is amorphous at the same wt $\%$, no yielding is observed (comparison of CCO and CC2 in Table 7). The increase in the yield stress and initial modulus which is observed from $\mathrm{CC} 1$ to $\mathrm{CC} 3$ (Table 7, Figure 9b) actually parallels the increase in crystallinity $\left(\Delta H_{\mathrm{m}}\right)$ which has been reported in Table 6 and in agreement with recent data on the effect of crystallinity of the deformed material on yielding and yield stress [22]. 

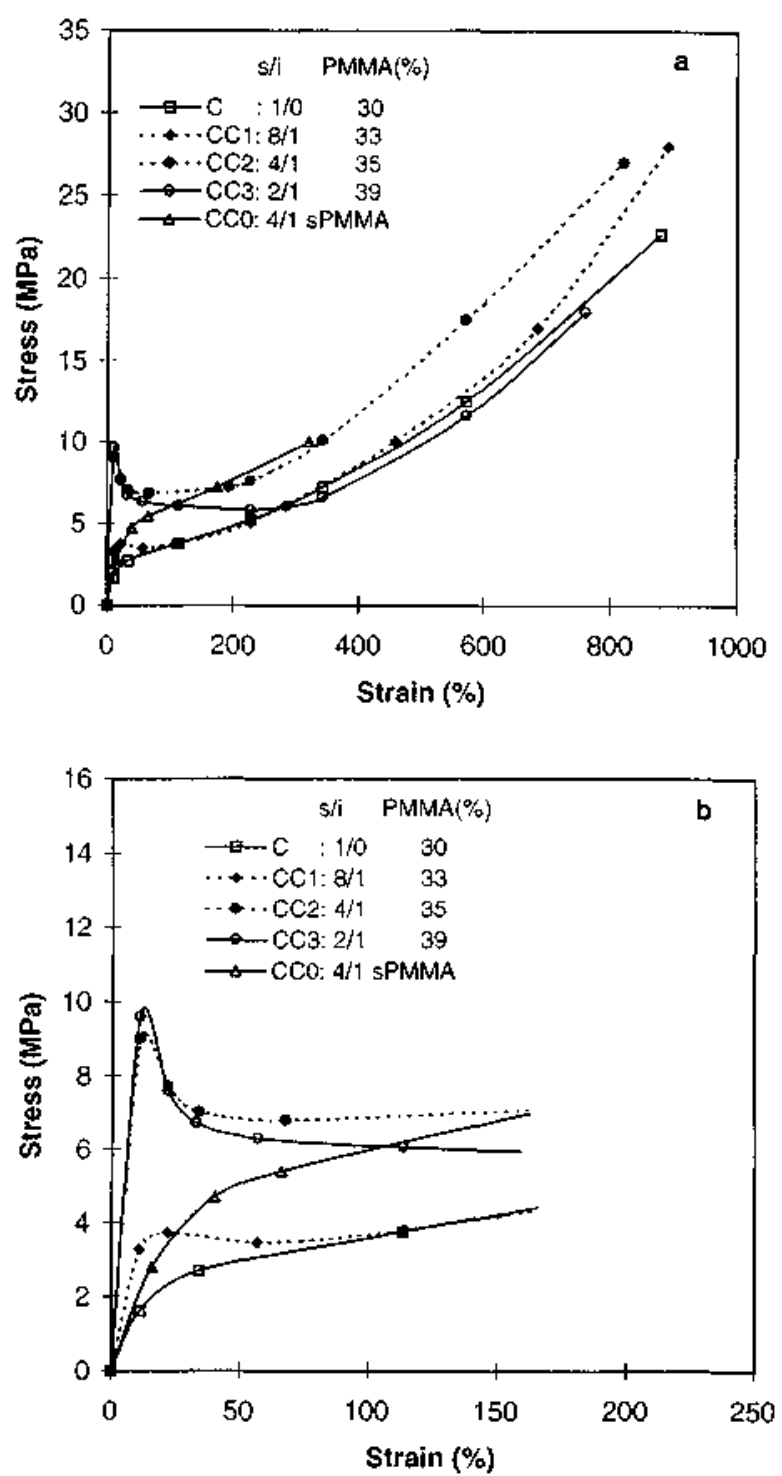

Figure 9 Stress-strain curves for the MBM triblock copolymer $C$ and blends with iPMMA3 at different s/i mixing ratios and with SPMMA at a 4/1 mixing ratio, (a) Full curves, (b) curves in the small strain region

The increase in the relative amount of the hard phase is detrimental to ductility as supported by a decrease of the ultimate properties, which occurs earlier when the hard phase is amorphous (comparison of CCO with $\mathrm{CC} 2$ and $\mathrm{CC} 3$, with respect to the pure triblock $\mathrm{C}$ ).

A further increase in the sPMMA content of the MBM triblock until $40 \mathrm{wt} \%$ at a constant total molecular weight (copolymer D) does not significantly change the main characteristics of the stress-strain behaviour and its dependence on the s/i ratio (Table 7). The same conclusion holds when the MBM triblock F is used, which has the same sPMMA content as copolymer D but a smaller molecular weight. The only difference between these two copolymers is that yielding only occurs in the triblock of the highest molecular weight.

It is worth noting that the necking range is very large for samples DC2 and DC3 (Figure 10) since it extends over an elongation of $c a .400 \%$ at a constant tensile stress. This behaviour is different from the pure MBM copolymer of a high sPMMA content in which the necking is less pronounced, since the tensile stress is not constant over a large elongation range. When necking is observed, the permanent set is continuously increasing upon the iPMMA addition. In this respect, it is known that necking is an irreversible deformation, usually responsible for the large permanent set observed for semi-crystalline materials [22]. This conclusion could thus be extended to the microdomains formed by the stereocomplex.

Figure 11 summarizes the ultimate properties of block copolymers B, C, D and their stereocomplex with iPMMA3 at various s/i mixing ratios. Stereocomplexation enhances the tensile properties of the MBM copolymer when the sPMMA content is low (copolymer B), in agreement with the observation by Kennedy et al. [6]. When sPMMA content is higher $(>30 \%)$, the enhancement of tensile strength is restricted to the range of low $\mathrm{i} / \mathrm{s}$ mixing ratios, with a maximum for a mixing ratio that depends on the block copolymer composition. 
When a MSBSM pentablock copolymer $(\mathrm{H})$ is blended with iPMMA3 in a 2/1 s/i ratio, the ultimate properties are affected.
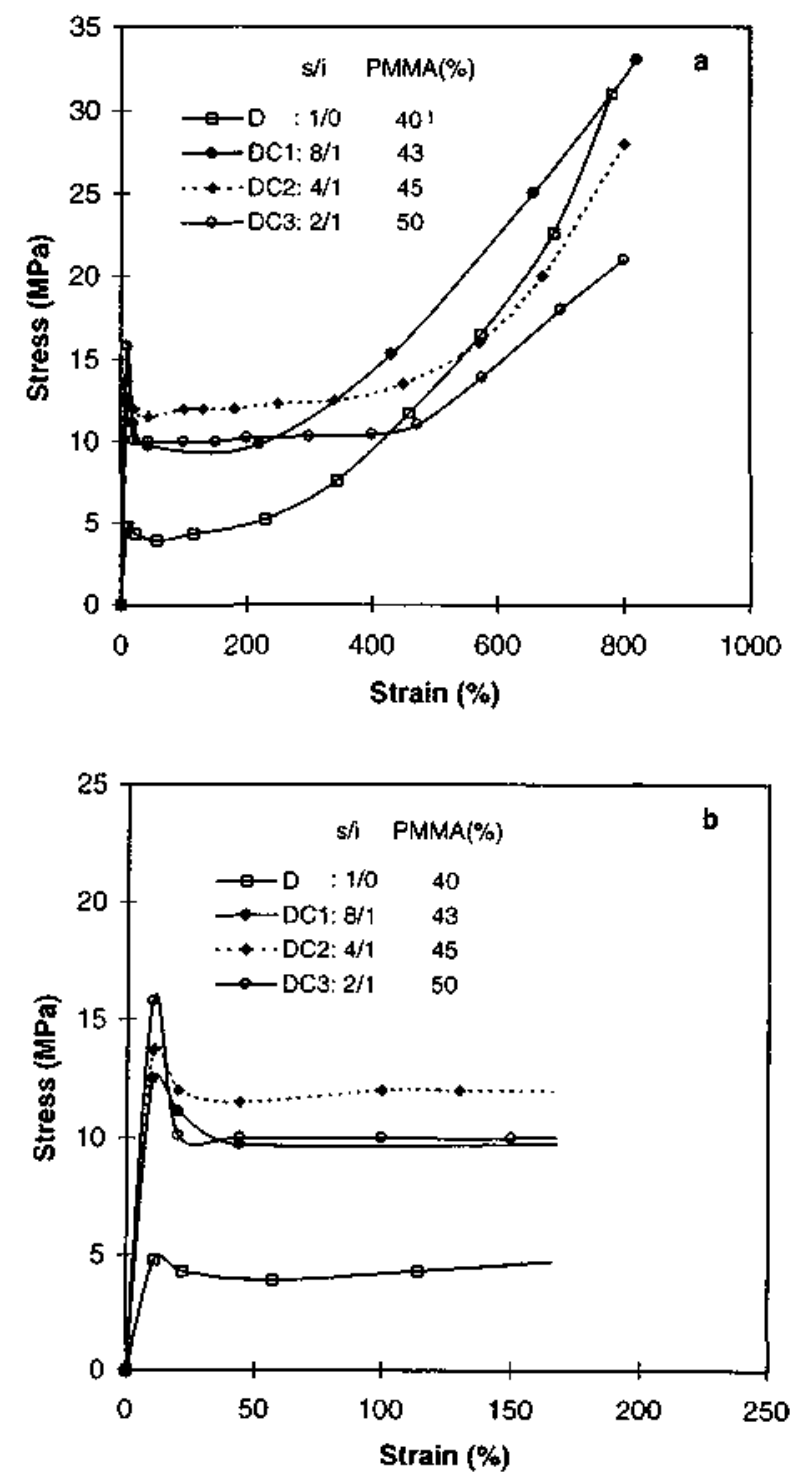

Figure 10 Stress-strain curves for the MBM triblock copolymer D and blends with iPMMA3 at different s/i mixing ratios. (a) Full curves, (b) curves in the small strain region

In agreement with observations reported for MBM triblocks, the ultimate properties are adversely affected, yielding is observed and a significant increase in the initial modulus as well. This effect is consistent with the total content of the hard block (PMMA $+\mathrm{PS}=50 \%$ ) which is high enough for the stereocomplex formation to promote the mutual connection of the hard microdomains.

\section{CONCLUSIONS}

Solvent casting of blends of MBM triblock copolymer with iPMMA results in the stereocomplexation of the sPMMA blocks (s) and the iPMMA (i) rather than in the self-aggregation of iPMMA and/or sPMMA. This process is affected by the $\mathrm{s} / \mathrm{i}$ mixing ratio and the mixing solvent. Extent of the stereocomplexation $\left(\Delta H_{\mathrm{m}}{ }^{)}\right.$is the highest at the 2/1 s/i mixing ratio. At a constant s/i mixing ratio, $\Delta H_{\mathrm{m}}$ has been found to be maximum in THF which is a complexing solvent and a common solvent for the two blocks of the MBM copolymers. $\Delta H_{\mathrm{m}}$ is minimum in chloroform which is a common solvent for the PBD and sPMMA blocks and a non-complexing solvent for the PMMA stereoisomers. The iPMMA molecular weight in the range of 3000 to 30000 and the sample stretching do not affect the thermal stability $\left(T_{\mathrm{m}}\right)$ of the stereocomplex, which is however dependent on the casting solvent. 

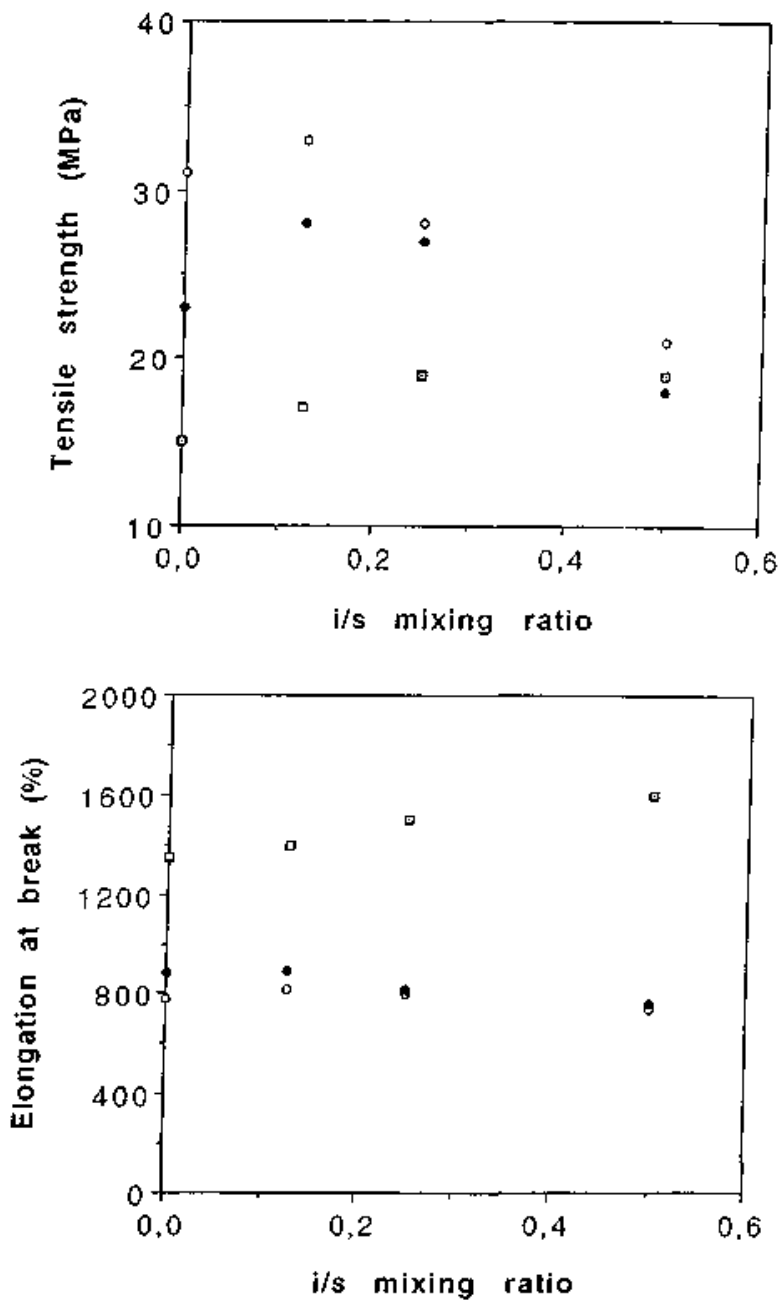

Figure 11 Ultimate tensile strength and elongation at break for the MBM triblock copolymers $B(\square), C(\bullet), D$ (O) and their blends with iPMMA3 at different $i / s$ mixing ratios

$T_{\mathrm{m}}$ is particularly low in chloroform and in a 1/9 cyclohexane/THF mixture, where cyclohexane is a selective solvent for the PBD block. Differences in thermal stability due to the casting solvent are largely erased by annealing at $140^{\circ} \mathrm{C}$.

Effect of stereocomplexation on the mechanical properties of MBM triblock copolymers is mainly governed by the composition of the block copolymer. When triblock copolymers of low PMMA content (12 wt $\%$ for example) are blended with iPMMA, the ultimate mechanical properties are improved when the s/i ratio is decreased down to 2/1. In contrast, when the PMMA content of the triblock copolymer is high enough (e.g. $30 \mathrm{wt} \%$ ), the opposite effect is observed, particularly in the range of s/i ratio smaller than $8 / 1$. For these copolymers, formation of the semi-crystalline stereocomplex has a favourable effect on the yielding process. As a rule, there is an increase in the yield stress and the initial modulus when the melting enthalpy of the stereocomplex is increased. The same general behaviour is observed for MSBSM pentablock copolymers.

\section{ACKNOWLEDGEMENT}

The authors are very much indebted to the Flemish Institute for the Promotion of Science-Technological Research in Industry (IWT) for the financial support of a joint research program with Raychem N.V. (Kessel-Lo, Belgium) and the Katholieke Universiteit Leuven (Prof. H. Berghmans and H. Reynaers). They warmly thank Dr N. Overbergh and R. Graulus (Raychem N.V.) for stimulating discussions. They are also indebted to Prof. H. Reynaers and H. Berghmans for WAXS measurements. They are grateful to the 'Services Fédéraux des Affaires Scientifiques, Techniques et Culturelles' for general support in the frame of the 'Poles d'Attraction Interuniversitaires: Polymères'. Ph. Dubois is a research associate of the Belgian National Fund for Scientific Research (FNRS). 


\section{REFERENCES}

[1] Fetters, L. J. and Morton. M. Macromolecules 1969, 2, 453

[2] Morton. M. and Mikesell, S. L. J. Macromol. Sci-Chem. 1993, A7, 1391

[3] Ladd, B. J. and Hogen-Esch, T. E. Polvm. Prepr. 1989, 30, 261

[4] Long, T. E., Broske, A. D., Bradley, D. J. and McGrath, J. E. J. Polvm. Sci. J. Polym. Chem. Edn 1989, 27,4001

[5] Kennedy. J. P. and Price, J. L. Polvm. Mater. Sci. Eng. 1991, 64

[6] Kennedy. J. P., Price. J. L. and Koshimura, K. Macromolecules 1991, 24, 6567

[7] DePorter. C. D., Ferrence, G. M. and McGrath, J. E. Polvm. Prepr. 1993. 34, 574

[8] Morton, M. 'Research on Anionic Triblock Copolymers, Thermoplastic Elastomers' (Eds N. R. Legge, G. Holden and H. E. Schroeder). Munich, Vienna, New York, 1987, p. 67

[9] Fox, T. F., Garrett, B. S., Goode, W. E., Gratch. S., Rincaid, J. F.. Spell, A. and Stroupe, J. D. J. Am. Chem. Soc. 1958, 80, 1768

[10] Spevacek, J. and Schneider, B. Adv. Colloid. Interface Sci. 1987, 27,81

[11] Feitsma. E. L., DeBoer, A. and Challa, G. Polymer 1975, 16, 515

[12] Schomaker. E. and Challa, G. Macromolecules 1988. 21. 2195, 3506

[13] Hclary, G., Bclorgey, G. and Hogen-Esch, T. E. Polymer 1992, 33. 1953

[14] Lemieux. E. Thesis, University Laval, Quebec, 1988

[15] Miyamoto, T. and Inagaki, H. Polvm. J. 1970, 1.46

[16] Ute, K,, Miyatake, N., Osugi. Y. and Hatada, K. Polym. J. 1993.25, 1153

[17] Spevacek. J. and Schneider, B. Makromol. Chem. 1974. 175, 2939

[18] Katime. I. A. and Quintana, J. R. Makromol. Chem. 1988. 189, 1373

[19] Hatada, K., Ute. K.. Tanaka. K.. Kitayama, T. and Okamoto, Y. Polvm. J. 1985. 17,977

[20] Duering, H.. Alberda Van Ekenstein, G. O. R., Challa, G., Mason. J. P. and Hogen-Esch, T. E. Macromolecules 1995. 28.1952

[21] Yu, .1. M.. Dubois. Ph.. Jerome. R. and Teyssic, Ph. Submitted to Macromolecules 1996, 29, 6090

[22] Kennedy, M. A., Peacock, A. J., Failla, M. D., Lucas, J. C. and Mandelkern, L. Macromolecules 1995, 28.1407

[23] Morton, M. and McGrath, J. E. J. Polym. Sci. 1969, C(26), 99

[24] Morton, M. Rubber Chem. Tech. 1983, 56, 1096

[25] Beecher. J. F. and Bradford, R. D. J. Polvm. Sci. 1969, C(26). 117

[26] Buter. R.. Tan, Y. Y. and Challa. G. J. Polym. Sci.. Polvm. Chem. Edn 1973. 11. 2973 